\title{
ANALYTICAL AND EXPERIMENTAL STUDY ON REPAIR EFFECTIVENESS OF CFRP SHEETS FOR RC BEAMS
}

\author{
Moatasem M. FAYYADH, H. Abdul RAZAK \\ Department of Civil Engineering, Faculty of Engineering, University of Malaya, 50603 Kuala Lumpur, \\ Malaysia
}

Received 14 Dec 2011; accepted 3 Jan 2012

\begin{abstract}
This paper presents the results of both analytical and experimental study on the repair effectiveness of Carbon Fibre Reinforced Polymer (CFRP) sheets for RC beams with different levels of pre-repair damage severity. It highlights the effect of fixing CFRP sheets to damaged beams on the load capacity, mid-span deflection, the steel strain and the CFRP strain and failure modes. The analytical study was based on a Finite Element (FE) model of the beam using brick and embedded bar elements for the concrete and steel reinforcement, respectively. The CFRP sheets and adhesive interface were modelled using shell elements with orthotropic material properties and incorporating the ultimate adhesive strain obtained experimentally to define the limit for debonding. In order to validate the analytical model, the FE results were compared with the results obtained from laboratory tests conducted on a control beam and three other beams subjected to different damage loads prior to repair with CFRP sheets. The results obtained showed good agreement, and this study verified the adopted approach of modelling the adhesive interface between the RC beam and the CFRP sheets using the ultimate adhesive strains obtained experimentally.
\end{abstract}

Keywords: CFRP repair system, CFRP debonding strain, adhesive modelling, failure modes.

Reference to this paper should be made as follows: Fayyadh, M. M.; Razak, H. A. 2014. Analytical and experimental study on repair effectiveness of CFRP sheets for RC beams, Journal of Civil Engineering and Management 20(1): 21-31. http://dx.doi.org/10.3846/13923730.2013.799095

\section{Introduction}

Most research on using FRP plate bonding for flexural strengthening was carried out in the last decade (Ritchie et al. 1991; Saadatmanesh, Ehsani 1991; Triantafillou, Plevris 1992). There has been an explosive growth in the recent years, which resulted from the increasing global need for structural performance updating and retrofitting works. The strengthening and repair of RC structures has become increasingly important, especially in the last decade. Strengthening is usually needed to improve the performance of existing RC structures. A change in the capacity of a structure in service could be due to an increase or change in applied loads, for example, increase in traffic above bridges, addition of extra floors on an existing structure, or installation of new equipment. Many $\mathrm{RC}$ structures are damaged mostly due to various forms of deterioration, like cracks or large deflections. These are affected by different factors, such as earthquakes, vibrations, corrosion of reinforced bars and environmental changes.

Externally, Carbon Fibre Reinforced Polymer (CFRP) is one of the new materials used to strengthen or repair RC structures. It is particularly suitable for insitu rehabilitation, and has become an increasingly applied and important technology because of CFRP advantages, such as, availability in any length, corrosion-resistance, high tensile strength, low weight, low installation cost and flexibility of storage, transportation and use. Many experimental and analytical studies have been carried out on strengthening or repairing $\mathrm{RC}$ beams using various types of FRP, including those related to design criteria and failure modes.

Reporting tests and investigations have been reviewed by Almakt et al. (1998) to develop a thorough understanding of the behaviour of beams strengthened by CFRP plates. CFRP plates were found to increase the flexural capacity within certain limits (Almakt et al. 1998). Externally bonded CFRP plates were found to perform well under the effect of the impact loading (Erki, Meier 1999). Adding an anchoring system at the end of the plates can improve the impact performance of the strengthened beam (Erki, Meier 1999). Repair of a real bridge with externally bonded FRP plates was found to decrease the flexural stresses in the steel reinforcements and the mid-span deflection (Stallings et al. 2000). Strengthening of concrete beams with externally bonded FRP plates was found to increase the ultimate capacity by $70 \%$ and reduce the size and the density of the cracks 
along the beam length (Fanning, Kelly 2001). A significant increase in the ultimate capacity was observed after adding the externally bonded CFRP sheets (Nguyen et al. 2001). Ultimate capacity of strengthened beams increased by up to $230 \%$, and even for the preloaded beam before strengthening, the ultimate capacity significantly increased, which indicates good performance for repair situations (Rahimi, Hutchinson 2001).

Based on early studies of the last decade on the use of the bonded FRP plates to beam soffit as flexural system, a number of failure modes have been observed. These modes can be generally classified as: (1) flexural failure by FRP rapture; (2) flexural failure by crushing of concrete at compression; (3) shear failure; (4) concrete cover separation; (5) plate end interfacial debonding; (6) intermediate flexural crack induced interfacial debonding; and (7) intermediate flexural shear crack induced interfacial debonding (Ritchie et al. 1991; Saadatmanesh, Ehsani 1991; Triantafillou, Plevris 1992; Chajes et al. 1994; Sharif et al. 1994; Heffernan, Erki 1996; Arduini, Nanni 1997; Ross et al. 1999; Bonacci, Maalej 2000).

Strengthening of corroded RC beams with externally bonded CFRP plates was found to increase the ultimate capacity by $37-87 \%$ (Masoud et al. 2001). Strengthening of the RC beam with one layer of the CFRP plate was found to increase the ultimate capacity by $200 \%$ and strengthening with two layers increased it by $250 \%$ (Capozucca, Cerri 2002). Use of CFRP plates for repair of damaged prestress bridge beams restored a portion of the lost flexural stiffness and reduced the mid-span deflection (Klaiber et al. 2003). Repairing of corroded concrete beams with externally bonded CFRP sheets was found to increase the load capacity up to $30 \%$ (Kutarba 2004). Kachlakev et al. (2001) investigated the Finite Element (FE) modelling of RC structures strengthened using FRP laminates. They showed a good agreement between the FE modelling and the full-scale test in terms of load against mid-span defection. The FE model shows higher stiffness than the experiential approach, which can be due to the effect of the bond slip between the concrete and steel reinforcement, and the micro-cracks occurring in the actual beams, which were excluded in the FE model. Issues related to ductility of FRP strengthening of RC flexural members, that is, the ability of materials to sustain plastic deformation before fracture, were studied by Delpak (2002). The results showed that the load capacity of the strengthened section increased up to $125 \%$ based on the FE method, and the deflection at the ultimate increased up to $24 \%$.

Modelling of RC beams strengthening with externally bonded FRP plates using nonlinear FE analysis was done by Supaviriyakit et al. (2004). They modelled the FRP plate as 8-nodeisoperimetric2D elastic element and the adhesive as perfect compatibility by directly connecting nodes of FRP with those of concrete. The study found that FE modelling can predict the load against deflection relation, ultimate load and failure modes correctly. Repairs of damaged RC beams with externally bonded CFRP sheets were carried out by Benjeddou et al. (2007). The study validates the effectiveness of the CFRP sheet as repairing technique for all the damage degrees. The peeling off failure mode was controlling the failure mechanism. The load capacity had increased by $87 \%$ for the strengthening beam when no pre-crack load was applied, and it was $44 \%$ for the highest damage degree. Choo et al. (2007) investigated the retrofitting of an actual bridge damaged under extreme loading using externally bonded CFRP sheets. The FE modelling was used to estimate the force emanated due to the extreme loads, and it also showed that repairing with CFRP sheets made a significant difference for the ultimate limit, while a small increase in the strength was observed for the service limit load.

Experimental investigation for the behaviour of RC structures strengthened with externally bonded CFRP sheets has been done by Ceroni (2010). Added CFRP sheets have increased the load capacity by $26 \%$ up to $50 \%$ in cases of the minimum steel reinforcement and $15 \%$ up to $33 \%$ for the case of maximum steel reinforcement. Ombres (2010) investigated intermediate crack debonding in reinforced concrete structures strengthened with externally bonded FRP sheets. The author derived and adopted a nonlinear local deformation model from cracking analysis based on the slip and bond stresses to predict the stress and strain distribution at failure. The FE modelling of the interface between the CFRP sheets and the concrete surface has been carried out by Obaidat et al. (2010). The study validated the modelling based on experimental work on RC beams in the laboratory. The CFRP sheets were modelled adopting two models: one with orthotropic material and another with elastic isotropic material. The study found that the perfect bond model was unable to model the softening behaviour of the beam. Use of CFRP sheets with U-shape anchorage can increase the capacity of the strengthened RC beam up to $10-24 \%$ depending on the number of U-shape anchorages along the beam length (El-Ghandour 2011). Repair of damaged steel beams with CFRP sheets increased the ultimate capacity up to $22.5 \%$ and the pre-repair levels did not affect the strain development in the CFRP sheets, while it did affect the debonding progression of the sheet (Kim, Brunell 2011). CFRP plates were found to be unaffected by the change in the environmental conditions due to superior quality control during the manufacture, while hand laid-up CFRP fabric was affected by the elevated temperature (Cromwell et al. 2011).

The present study aims to investigate the effect of different pre-repair damage levels on the repairing effectiveness using externally bonded CFRP sheets. It will highlight the effect of fixing CFRP sheets to damaged beams on the load capacity, mid-span deflection, the steel strain, the CFRP strain and failure modes. The study will suggest a method to model the adhesive interface between the RC beam and the CFRP sheets based on the ultimate adhesive strain values carried out experimentally. The developed FE model of repaired RC beam using externally bonded CFRP sheets based on the ultimate adhesive strain will be compared with the results of the experimental approach in terms of load against defection, load against the steel strain, load against CFRP strain and failure modes. 


\section{Experimental work}

In order to investigate and validate the effect of the prerepair damage level on the effectiveness of CFRP sheets as a repairing system, four RC beams were prepared for the tests, where for each beam the clear span length is $2.2 \mathrm{~m}$ and beam cross section is $150 \mathrm{~mm}$ wide and $250 \mathrm{~mm}$ deep (dimensions were scaled down to actual beam due to laboratory facilities and equipment limitations). Beams were designed according to ACI 318 (2008) Code requirements, where beams were reinforced with two $12 \mathrm{~mm}$ diameter deformed steel bars. Figure 1 and 2 show details of the beams and the test setup. Table 1 shows details of the RC beams. The RC beams were tested under point load located at mid-span. Load was applied gradually with a loading rate of $4 \mathrm{kN} / \mathrm{min}$. One of the beams was

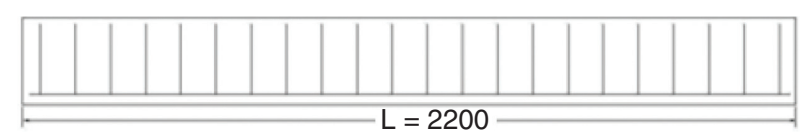
a-Longitudinal Section

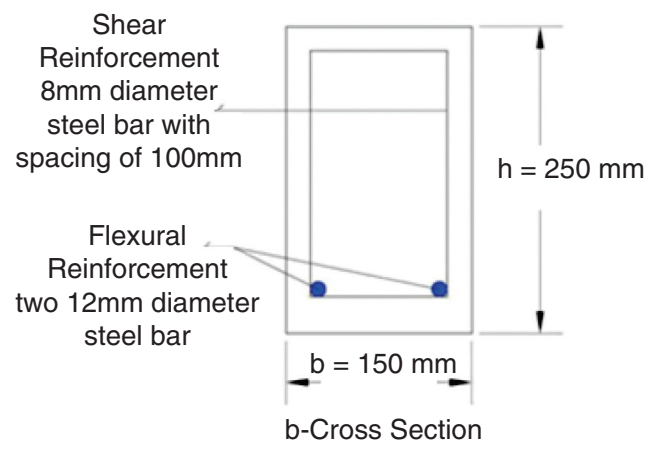

Fig. 1. RC beam dimensions and details

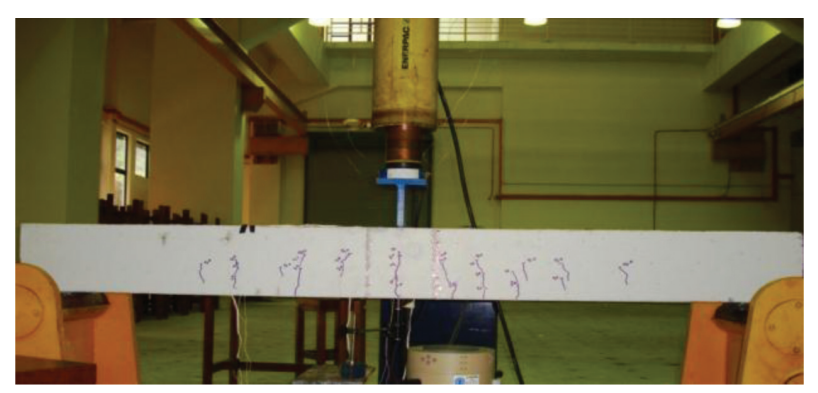

Fig. 2. Beam under static test used as the datum and was tested under cyclic loading of $10 \mathrm{kN}$ for each cycle up to failure. The repaired beams were initially damaged under design limit load, steel yield limit load and ultimate load. For repairing, beams were turned over and roughness equipment was used on the tension face to get a suitable face and have as much as possible fraction with the CFRP sheet. Figure 3 shows the beam surface after roughness equipment was used and the CFRP sheets were fixed. The surface was cleaned by using air pressure to avoid any dust on the surface, as the substrates must be sound, dry, clean and free from laitance, ice, standing water, grease, oils, old surface treatments or coatings and all loosely adhering particles. The concrete was cleaned and prepared to achieve a laitance and contaminant free, open textured surface. When the concrete surface was prepared, the CFRP sheet was fixed by using adhesive material and then was left for one month for hardening. Repairing with CFRP sheet was designed according to ACI 440.2R (2002) Code requirements with a $100 \mathrm{~mm}$ width and $1.2 \mathrm{~mm}$ thickness and the length was the clear span of the beam. The CFRP properties are shown in Table 2. Static load was gradually applied again on the repaired beams with an increase rate of $4 \mathrm{KN} / \mathrm{min}$ up to failure. During the test, load against deflection data, the steel strain and CFRP strain was carried out. Failure modes were highlighted.

\section{Finite element modelling}

This part presents the simulating of the experimental work setup and samples. The undertaken cases were as unrepaired beam and three repaired beams. The repair of the beam was designed according to ACI 420.2R (2002) Code, where a CFRP sheet with $100 \mathrm{~mm}$ width and $1.2 \mathrm{~mm}$ thickness was fixed on the tension face of the $\mathrm{RC}$ beam and along the clear span of the beam. The modelling of the $\mathrm{RC}$ beam was done using the 20 -node brick elements to represent the concrete. In addition, a 2-node embedded bar inside a 3-D brick element was used to represent the reinforcement bars and 4-node two-dimensional curved shell elements were used to represent CFRP sheets as composite material. The adhesive interface was modelled by using the 4-nodes two-dimensional curved shell elements as composite material. Figure 4 shows the FE modelling for the RC beam. Concrete was modelled using smeared crack model. For concrete, the linear behaviour was modelled as isotropic material with certain compressive strength value, modulus of elasticity, Poisson's ratio

Table 1. RC beam properties

\begin{tabular}{|c|c|c|c|c|c|c|}
\hline Beams & $\begin{array}{c}\text { Steel bar } \\
\text { diameter mm }\end{array}$ & $\begin{array}{l}\text { Steel tensile } \\
\text { stress } \mathrm{MPa}\end{array}$ & $\begin{array}{l}\text { Rupture steel } \\
\text { stress } \mathrm{MPa}\end{array}$ & $\begin{array}{c}\text { Concrete } \\
\text { compressive } \\
\text { strength } \mathrm{MPa}\end{array}$ & $\begin{array}{c}\text { Concrete tensile } \\
\text { stress } \mathrm{MPa}\end{array}$ & $\begin{array}{l}\text { Pre-repair damage } \\
\text { statute load rate }\end{array}$ \\
\hline G1D & 12 & 535 & 665 & 39.4 & 3.8 & N/A \\
\hline G2R1 & 12 & 535 & 665 & 36 & 3.15 & Design limit \\
\hline G3R2 & 12 & 565 & 785 & 36 & 3.4 & Steel yield limit \\
\hline G3R3 & 12 & 565 & 785 & 35 & 3.42 & Failure load \\
\hline
\end{tabular}



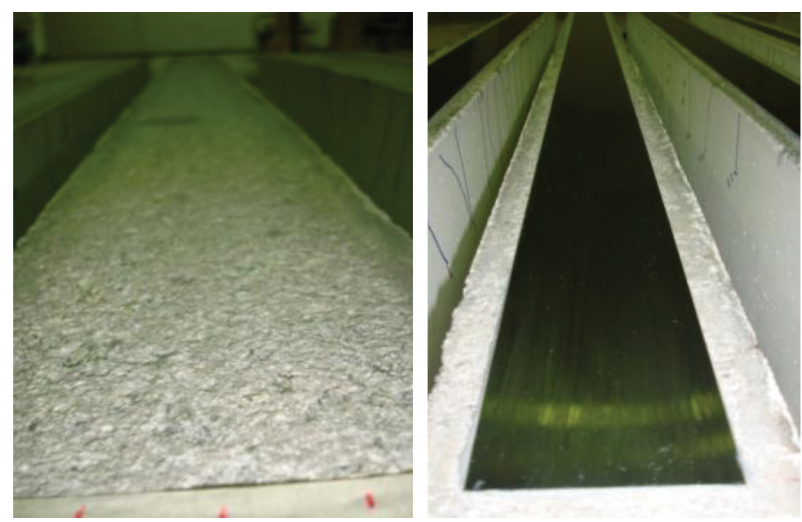

Fig. 3. Surface preparation and CFRP fixing

Table 2. CFRP sheet properties in three dimensions

\begin{tabular}{lcc}
\hline & $\begin{array}{c}\mathrm{X} \\
\text { (longitudinal) }\end{array}$ & $\begin{array}{c}\text { Y\&Z } \\
\text { (transfer) }\end{array}$ \\
\hline Tensile strength (MPa) & 2800 & 28 \\
Modulus of Elasticity (MPa) & 165,000 & 1650 \\
Ultimate strain $(\mathrm{mm} / \mathrm{mm})$ & 0.017 & 0.00017 \\
\hline
\end{tabular}

and mass density. For nonlinear behaviour, it was modelled using linear stress cut-off, linear tension softening, ultimate strain based and constant shear retention models. The concrete properties were as shown in Table 1. Reinforcement steel bars were represented as bonded reinforcement and for steel nonlinearity, the Von-Mises plasticity criteria was used with work hardening rule to present the actual steel stress-strain curves. The tensile test was carried out on steel bar samples and the stress-strain curves were as shown in Figure 5. Reinforcement steel bars were given properties as shown in Table 1 above. CFRP sheet was represented as a composite material with Hill-Orthotropic plastic model using yield. The CFRP was given by the material producer as shown in Table 2. The adhesive interface was modelled as composite material using HillOrthotropic plastic model and using yield Stress-Princip anisot and was given the actual debonding strain, which was found while carrying a static load test and as shown in Table 3. Both CFRP sheets and the adhesive layer were modelled as orthotropic material, which has higher strength in the longitudinal direction and no strength in the transfer directions.

\section{Results and discussion}

This section will present the results obtained in the present study. The section will present the influence of fixing CFRP sheets to the RC beams on the load capacity, the steel strain and the CFRP strain; and will highlight the effect of the pre-repair damage level on the load capacity of the repaired beams. Moreover, the comparison between the FE modelling and the experimental approach results in terms of load against deflection, load against the steel strain and load against CFRP strain curves will be presented.

\subsection{Influence of the CFRP on the RC beams}

This section will present the effect of fixing CFRP sheets to the beam on its stiffness and capacity with the aid of load against deflection curves, load against steel strain curves, the effect of the pre-repair damage load rate on the load against CFRP strain curves and the ultimate capacity rates. At the pre-repair phase, beam G1D wasn't exposed to any load, beam G2R1 was exposed to damage load of $25 \mathrm{kN}$, beam G3R2 was exposed to damage load of $55 \mathrm{kN}$ and beam G4R3 was exposed to $86 \mathrm{kN}$. Figure 6 presents the comparison of load against cumulative mid-span deflection at the post-repair phase for the four tested beams.

The results show that fixing CFRP sheets to the tension face of the beam have increased the load capacity of the beams regardless of the pre-repair damage level. Fixing the CFRP has reduced the deflection of the beam mid-span. The beam G4R3 which is damaged under ultimate capacity of $86 \mathrm{kN}$ of the pre-repair phase has higher deflection than the other two repaired beams, because of the reduction of the stiffness due to the damage load. The failure mode of the beam G1D, which is the unrepaired beam, was a flexural failure followed by concrete crushing; while for beams G2R1, G3R2 and G4R3 the failure was due to intermediate crack induced
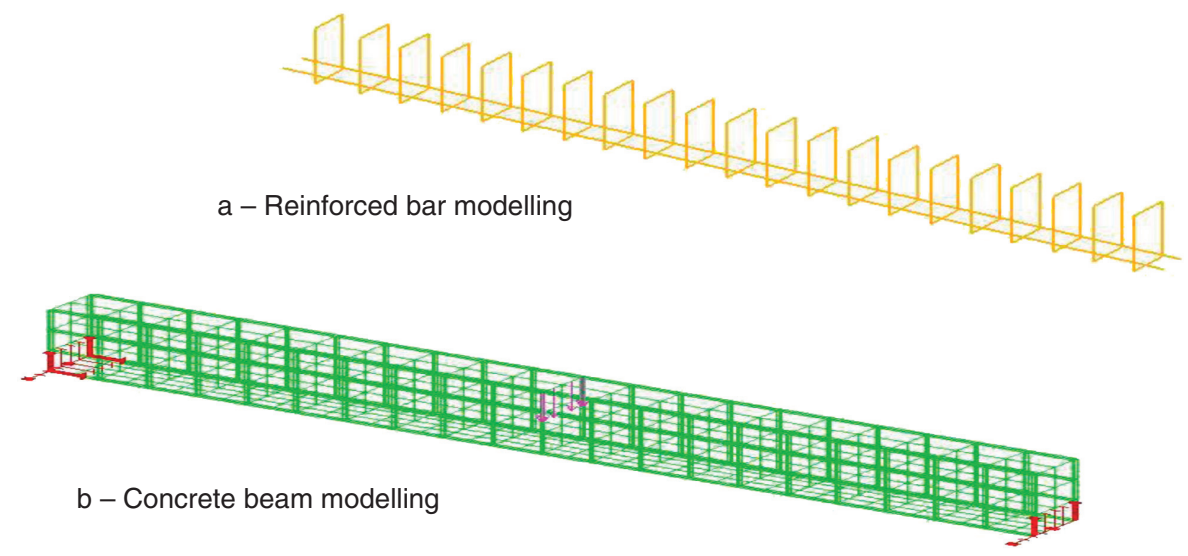

Fig. 4. Finite element model of reinforced concrete beams 


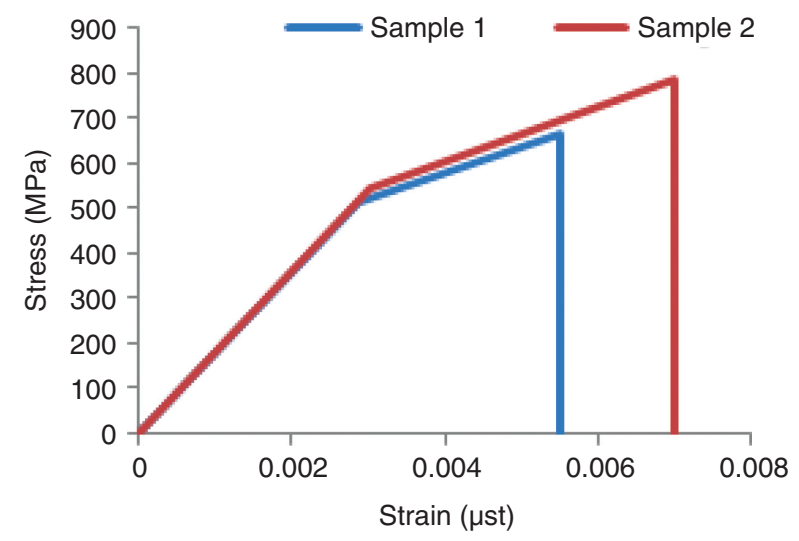

Fig. 5. Stress-strain curve for the steel reinforced bar (Sample 1 for beams G1D \& G2R1, sample 2 for beams G3R2 \& G4R3)

Table 3. Adhesive interface properties

\begin{tabular}{llcc}
\hline & \multicolumn{3}{c}{ Adhesive layer of $2 \mathrm{~mm}$ thickness } \\
\cline { 2 - 4 } & & $\begin{array}{c}\mathrm{X} \\
\text { (longitudinal) }\end{array}$ & $\begin{array}{c}\text { Y\&Z } \\
\text { (transfer) }\end{array}$ \\
\hline G2R1 & Tensile strength $\mathrm{MPa}$ & 75.6 & 0.756 \\
& Modulus of Elasticity MPa & 12,000 & 12,000 \\
& Ultimate strain $\mathrm{mm} / \mathrm{mm}$ & $6.1 \mathrm{E}-3$ & $6.1 \mathrm{E}-5$ \\
\hline G3R2 & Tensile strength MPa & 64.8 & 0.648 \\
& Modulus of Elasticity MPa & 12,000 & 12,000 \\
& Ultimate strain $\mathrm{mm} / \mathrm{mm}$ & $5.4 \mathrm{E}-3$ & $5.4 \mathrm{E}-5$ \\
\hline G4R3 & Tensile strength $\mathrm{MPa}$ & 70.8 & 0.708 \\
& Modulus of Elasticity MPa & 12,000 & 12,000 \\
& Ultimate strain $\mathrm{mm} / \mathrm{mm}$ & $5.9 \mathrm{E}-3$ & $5.9 \mathrm{E}-5$ \\
\hline
\end{tabular}

debonding (IC) of the CFRP sheets. Figure 7 shows the load cycles corresponding to the steel strain at mid-span for the tested beams, except beam G4R3 where the strain gauge wires were broken off when the failure started to occur under a loading rate of $86 \mathrm{kN}$ of the pre-repair phase.

The curves show that the presence of CFRP sheets has reduced the steel strain value for the same loading rate. Beam G2R1 has a smaller strain than beam G3R2 due to the strain level of the pre-repair phase. For G2R1, the steel reaches the strain of $1480 \mu \mathrm{st}$, while for G3R2 the steel reaches the strain of $2600 \mu$ st, which reduces the stiffness of the steel bars. The steel reaches the rupture strain at $5500 \mu$ st (see Fig. 5, sample 1) when the failure of the beam G1D occurs, while at debonding of CFRP for the beam G2R1 the steel reaches a strain of $3900 \mu \mathrm{st}$, which is less than the rupture limit (see Fig. 5, sample 1). Similarly, for the beam G3R2 the steel reaches strain of $5000 \mu \mathrm{st}$, which is less than the rupture limit (see Fig. 5, sample 2). Figure 8 presents the load against CFRP strain curves for the post-repair phase of the tested beams.

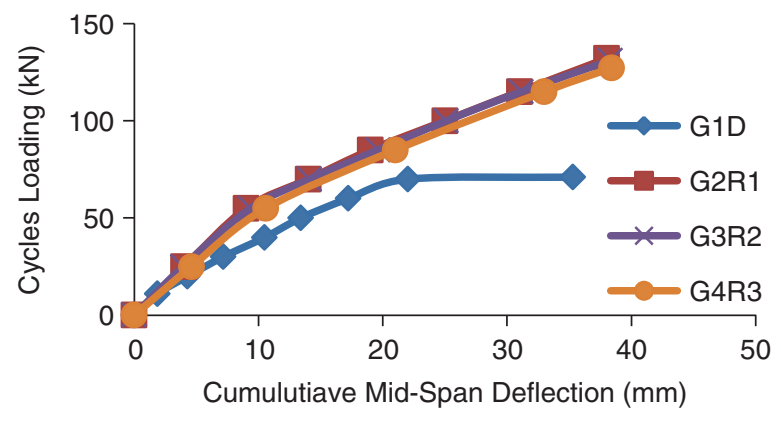

Fig. 6. Load against deflection curves for the tested beams

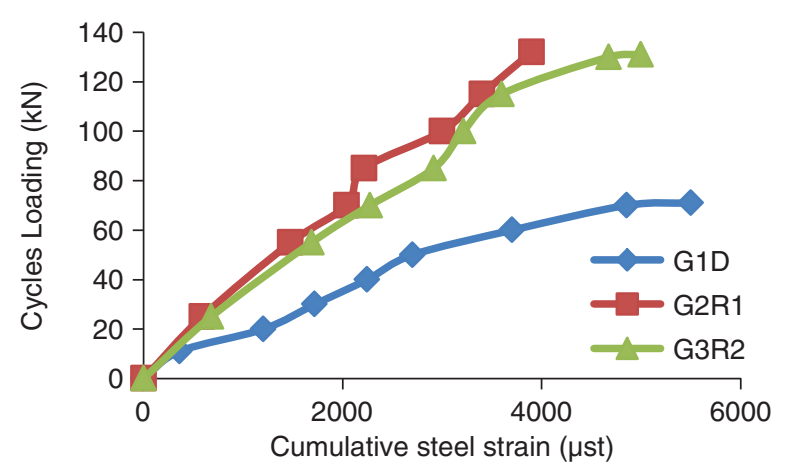

Fig. 7. Load against the cumulative steel strain of the tested beams

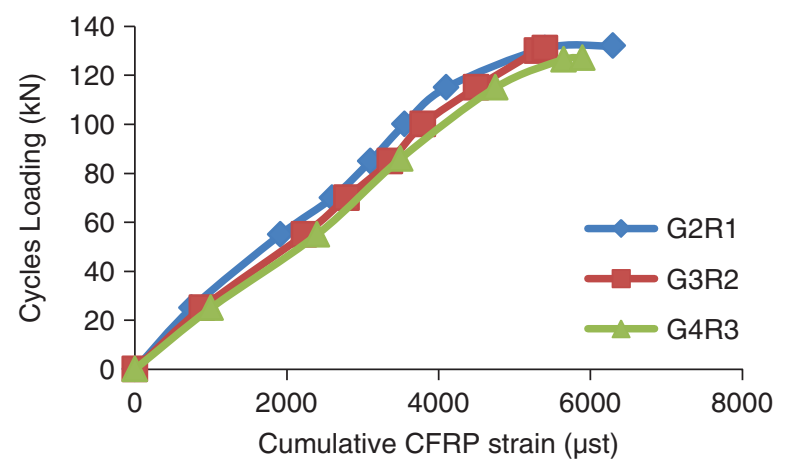

Fig. 8. Load against the cumulative CFRP strain of the tested beams

The results show that the pre-repair damage level influences the CFRP strain, with the CFRP having a higher strain for the higher damage level, as for the higher damage load rate at the pre-repair phase the steel reaches higher strain levels and loses its stiffness, which influences the repairing statuses of the beams with the CFRP having to share the maximum part of the tension stresses. The CFRP debonding occurs at a strain of $6100 \mu$ st for the beam G2R1, while it was $5400 \mu$ st and $5870 \mu$ st for beams G3R2 and G4R3, respectively. This can be because the steel of the beam G2R1 has the stress-strain curves of sample 1 as shown in Figure 5, while the steel of beams G3R2 and G4R3 has the stress-strain curve of sample 2 as shown in Figure 5, which means the steel of beam G2R1 has a lower rupture strain than for beams G3R2 and G4R3. Moreover, beams G3R2 and G4R3 have an ultimate 
capacity of the unrepair section of around $85 \mathrm{kN}$, while for beam G2R1 it is $71 \mathrm{kN}$, which leads to making the CFRP sheets of beam G2R1 take a strain of $6100 \mu$ st to achieve load capacity of $131 \mathrm{kN}$, while beams G3R2 and G4R3 take a strain of $5400 \mu$ st and $5870 \mu$ st to achieve load capacity of $130.7 \mathrm{kN}$ and $128 \mathrm{kN}$, respectively.

\subsection{Comparison of experimental and analytical results}

This section will present the experimental results and the corresponding analytical results. The section presents results related to the datum beam and three repair beams. The results include the load against deflection, load against the steel strain, load against CFRP strain curves and failure modes.

\subsubsection{Datum beam G1D}

G1D beam was used as the datum and to validate the analytical modelling of RC beam without externally bonded CFRP sheets. The beam was loaded with point load applied at the mid-span with cycles of $10 \mathrm{kN}$ up to failure. During each cycle, load against the deflection curve and load against the steel strain curve were recorded; and at failure, the failure mode was highlighted. Same beam was modelled using FE software, with the same material properties used and the same loading cycles adopted. Figure 9 shows the load against deflection curves for the beam based on the experimental result, as well as the analytical results. The deflection values were calculated as cumulative values by adding the unloading deflection from the previous loading cycle.

The results were almost the same and there was no noticeable difference between the experimental and the analytical results. The failure load was the same at $71 \mathrm{kN}$ and the failure mode was the same with flexural failure at the tension zone followed by concrete crushing. The load against steel strain curves were drawn based on the maximum reached for the steel strain at each loading cycle and cumulative with the residual steel strain from the previous cycle. Figure 10 shows the load against steel strain curves for both the experimental and the analytical results.

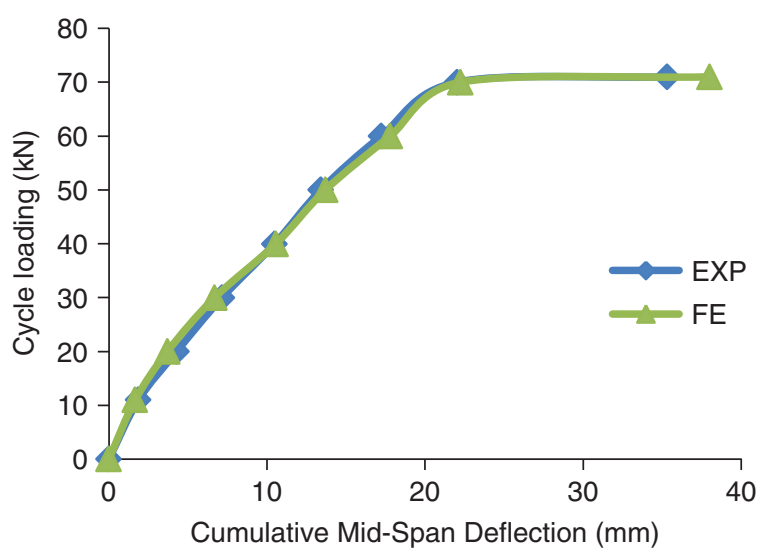

Fig. 9. Load against deflection curves for G1D (EXP refer to Experimental data and FE refer to Finite Element modelling data)

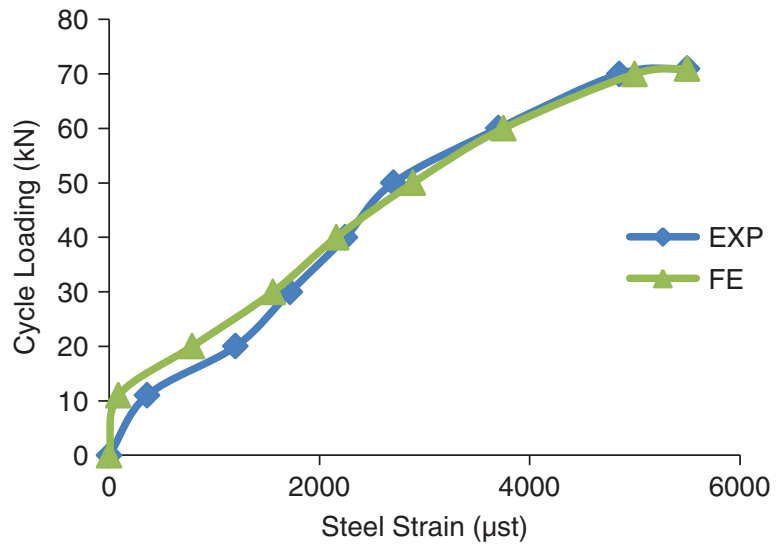

Fig. 10. Load against steel strain curves for beam G1D

The results show good agreement between the analytical and the experimental steel strain results. At early loading cycles the experimental results show higher strain, and up to $40 \mathrm{kN}$ both analytical and experimental results start to have similar values all the way to failure. For both FE modelling and experimental results the yield strain of $2860 \mu$ st occurs between loading cycles of 50 and $60 \mathrm{kN}$. The steel rupture strain was $5500 \mu$ st for both FE and EXP results.

\subsubsection{Repaired beam G2R1}

G2R1 was used as repaired beam. It was first exposed to the design limit load at $25 \mathrm{kN}$, then was strengthened with externally bonded CFRP sheets and finally exposed to the loading up to failure. For pre-repair phase, load against the deflection curve was drawn for both experimental and analytical results as shown in Figure 11.

The results show good agreement between the analytical and the experimental results which support the FE modelling as a good tool to simulate the experimental procedure. Figure 12 shows the load against steel strain curves for the pre-repair phase of G2R1.

The results show the immediate increase in the strain values when the first crack occurs, with the loading rate of $11 \mathrm{kN}$. The strain values at $25 \mathrm{kN}$ show a slight difference between the analytical and the experimental results. After

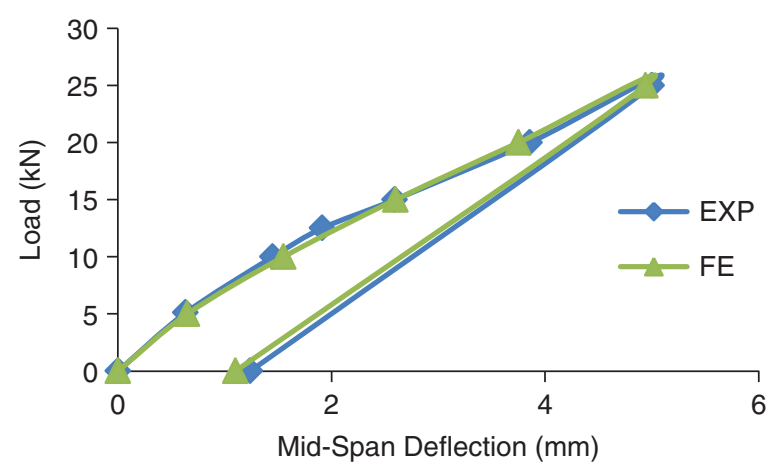

Fig. 11. Load against the deflection curve for pre-repair phase of the beam G2R1 


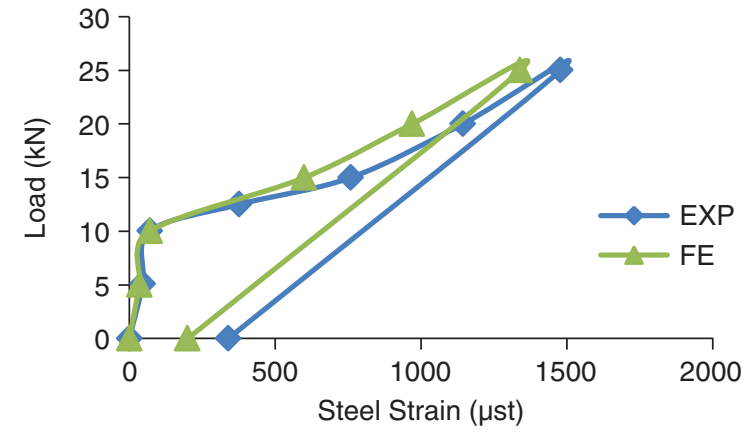

Fig. 12. Load against steel strain curves for pre-repair phase of the beam G2R1

repairing of the beam with externally bonded CFRP sheets, loading cycles were applied up to failure. The first cycle was up to the pre-repair damage load rate of $25 \mathrm{kN}$, the next cycle was up to the steel yield load rate, which is $55 \mathrm{kN}$, then up to the failure load rate for the nonstrengthened beam which is $70 \mathrm{kN}$, followed by cycles up to $85 \mathrm{kN}, 100 \mathrm{kN}, 115 \mathrm{kN}$ and $131 \mathrm{kN}$, where the CFRP debonding happened as intermediate crack induced debonding. After debonding of the CFRP, the beam was loaded again to get the failure load of the beam which was $71 \mathrm{kN}$, considered as the failure load of the unrepaired beam. The increase in the loading capacity of the strengthened beam was $184.5 \%$. Load against cumulative deflection for the post-repair phase of G2R1 is as shown in Figure 13.

The results show good agreement between the analytical and the experimental results. After the failure of the adhesive interface, the FE software stopped, highlighting the failure of the beam, while for the experimental results, after debonding of the CFRP sheets the beam still can take loading up to $71 \mathrm{kN}$. This failure load can be considered as the ultimate capacity of the unrepaired beam and is a good indicator of the ability of repair of the damaged beam after debonding of the CFRP sheets. Figure 14 shows the load against cumulative steel strain curves for the post-repair phase of G2R1.

The results show good agreement between the analytical and the experimental results, especially at the early cyclic loading up to the yield of the steel. Both results show that the steel yield occurs between cyclic loading of 85 and $100 \mathrm{kN}$, possibly due to the presence of

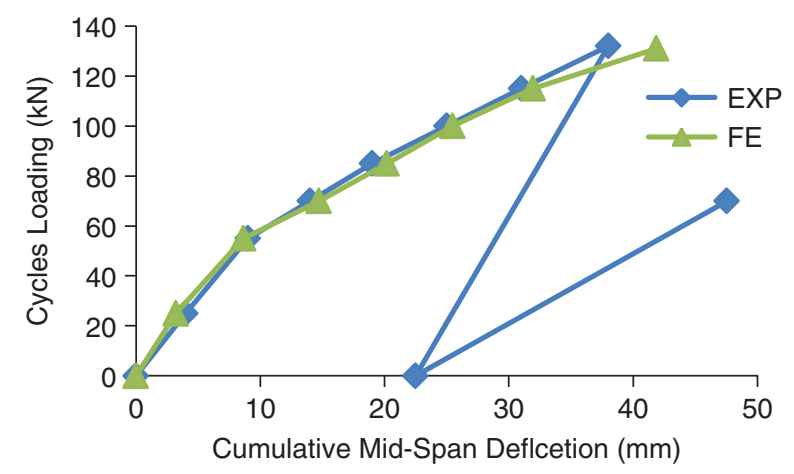

Fig. 13. Load against cumulative mid-span deflection for the post-repair phase of the beam G2R1

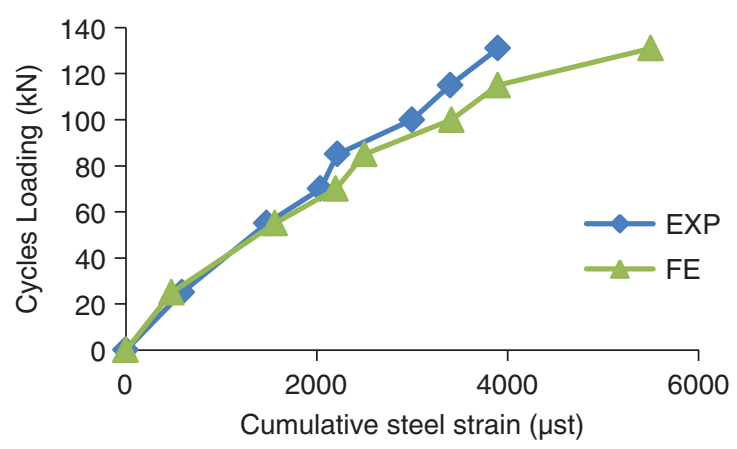

Fig. 14. Load against the cumulative steel strain for post-repair phase of the beam G2R1

the CFRP sheet leading to an increase in the steel yield loading rate with the CFRP sharing the tensile stresses with the steel bars. At failure, the analytical results show that steel reinforcement has reached the rupture strain at $5500 \mu$ st, which leads to full failure of the beam after debonding of the CFRP at $131 \mathrm{kN}$. The experimental results show that the steel reached less than $4000 \mu$ st, which means that steel was still in the hardening zone and could take more loading; this is the reason behind the ability of the beam to take loading after the CFRP debonding. Figure 15 presents the load against CFRP strain for the post-repair phase of G2R1. The results show good agreement between the analytical and the experimental results. Both results show that the debonding occurs at load of $131 \mathrm{kN}$ with CFRP strain of $6100 \mu$ st.

\subsubsection{Repaired beam G3R2}

This beam was used to investigate the damage cases when the steel just reaches the yield stage. The loading was applied to the beam mid-span and increased gradually. The steel strain was monitored and the loading was released when steel reached the yield stage at $3000 \mu$ st. The yield reached loading of $58 \mathrm{kN}$. Figure 16 shows the load against the deflection curve for the pre-repair phase of G3R2. The results show good agreement between analytical and experimental results and compatibility for loading up to $45 \mathrm{kN}$. Analytical results start to have smaller deflection than the experimental results up to $55 \mathrm{kN}$. Figure 17 shows the comparison between analytical and experimental results in terms of the steel strain.

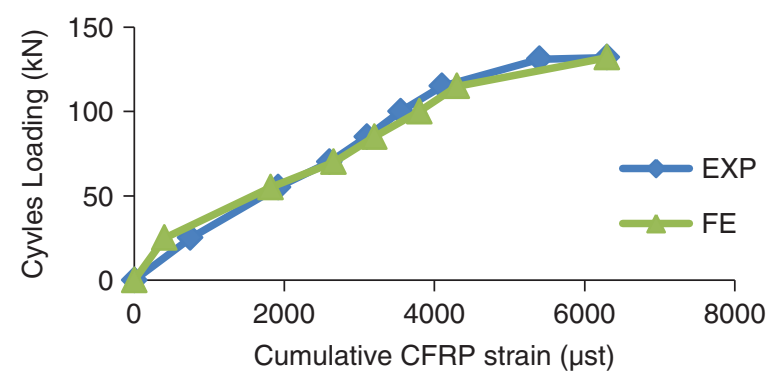

Fig. 15. Load against the cumulative CFRP strain for the postrepair phase of the beam G2R1 


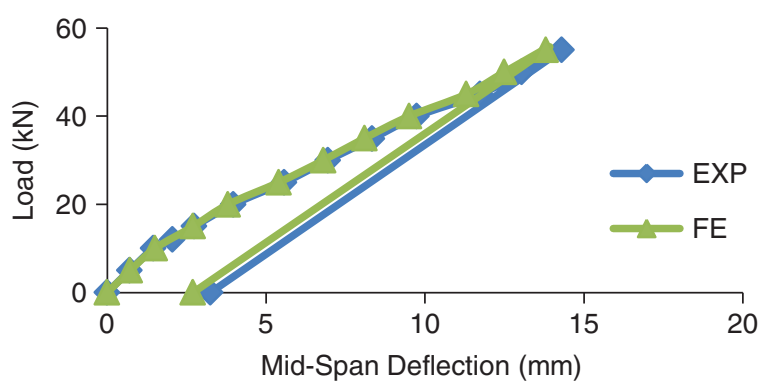

Fig. 16. Load against the deflection curve for pre-repair phase of the beam G3R2

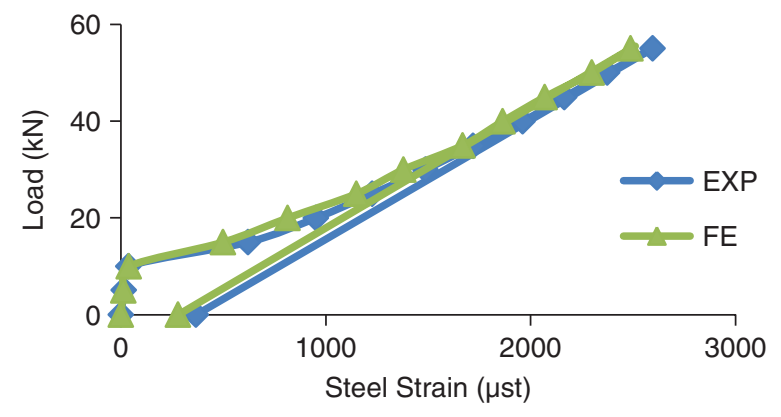

Fig. 17. Load against steel strain curves for pre-repair phase of the beam G3R2

The results show good compatibility between analytical and experimental results, and for higher loading the analytical results start to have smaller strain values than the experimental results. The curves show jumping in the strain values after loading of $10 \mathrm{kN}$ due to the appearance of the flexural crack, as when the crack occurs, the steel starts to take all the tension stresses.

The damaged beam was repaired by fixing externally bonded CFRP sheets and then was exposed to load up to failure. The loading was applied as cyclic, with the first cycle being up to the design limit load at $25 \mathrm{kN}$; the next cycle up to the pre-repair damage load at $55 \mathrm{kN}$; then $70 \mathrm{kN}, 80 \mathrm{kN}, 100 \mathrm{kN}, 115 \mathrm{kN}$, and $130.7 \mathrm{kN}$ when the intermediate crack induced debonding of the CFRP sheets occurred. After full debonding of the CFRP sheet, the steel was still unruptured, which led the beam to take loading up to $84 \mathrm{kN}$, considered to be the ultimate capacity of the unrepaired beam. Figure 18 presents the load against the cumulative deflection at mid-span for the loading cycles of the repaired beam.

The curves show good compatibility between analytical and experimental results. At loading cycles more than $70 \mathrm{kN}$, analytical results start to have lower deflection values and up to failure. At the debonding of the CFRP sheets, the analytical results show that the beam is already fully collapsed, while the experimental results show that the beam still can take further loading to fail at $84 \mathrm{kN}$, which is considered as the ultimate capacity of the unrepaired beam. The ability of the beam to take loading after the CFRP debonding can be because the steel did not yet rupture as is clear from Figure 19, which shows the load against the cumulative steel strain.

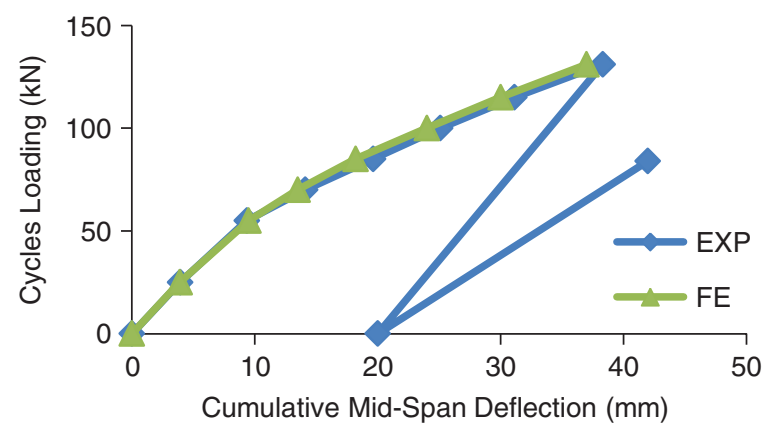

Fig. 18. Load against cumulative Mid-Span defalcation for the post-repair phase of the beam G3R2

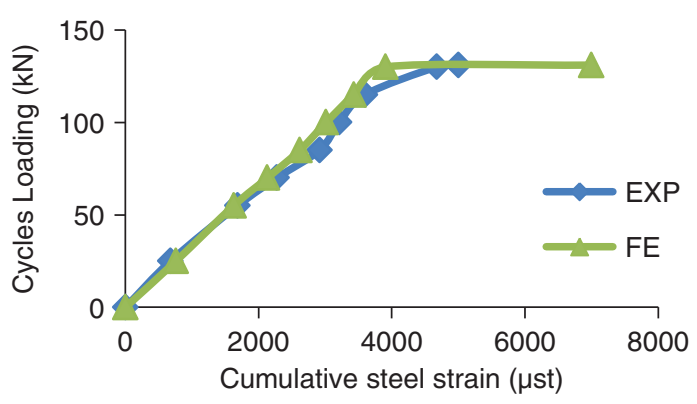

Fig. 19. Load against the cumulative steel strain for the postrepairing phase of the beam G3R2

The curves show good agreement between analytical and experimental results. At higher loads of more than $70 \mathrm{kN}$, there is a slight difference between analytical and experimental results, with analytical results showing smaller strain values. At load of $131 \mathrm{kN}$ when the CFRP debonding occurs, the analytical results show that the steel reaches the rupture strain at $7000 \mu$, while experimental results show that the steel reaches the strain of $5000 \mu$ st, which is still lower than the rupture limit. This is likely the reason why the beam is able to take loading up to $84 \mathrm{kN}$ after the CFRP debonding. The growth of the CFRP strain with the cycle loading was monitored and the results of the load against CFRP cumulative strain areas are shown in Figure 20. The results show good compatibility between analytical and experimental results, although the analytical results show smaller strain values for cycles loading between $20 \mathrm{kN}$ and $100 \mathrm{kN}$. The experimental results show that the CFRP strain reaches $5400 \mu$ st at debonding.

\subsubsection{Repaired beam G4R3}

This beam was used to investigate the damage cases when the beam reaches its ultimate capacity. The loading was applied to the beam mid-span and increased gradually; and the load against the deflection curve was monitored. Load application was stopped when the curve started to become a horizontal line, which meant it had reached the ultimate load capacity, with the ultimate load at $86 \mathrm{kN}$. Figure 21 shows the load against the deflection curve for the pre-repair phase of G4R3. 


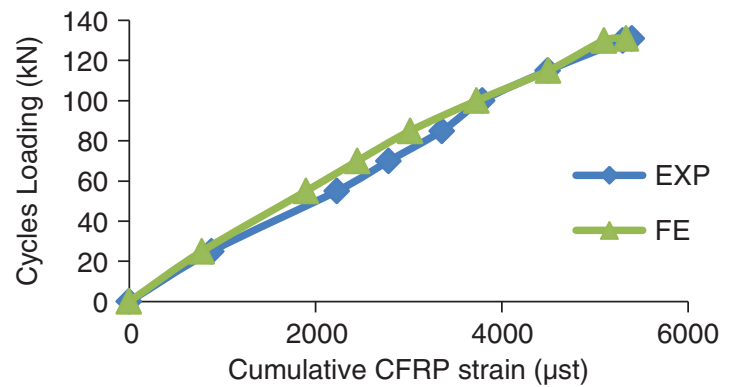

Fig. 20. Load against the cumulative CFRP strain for the postrepair phase of the beam G3R2

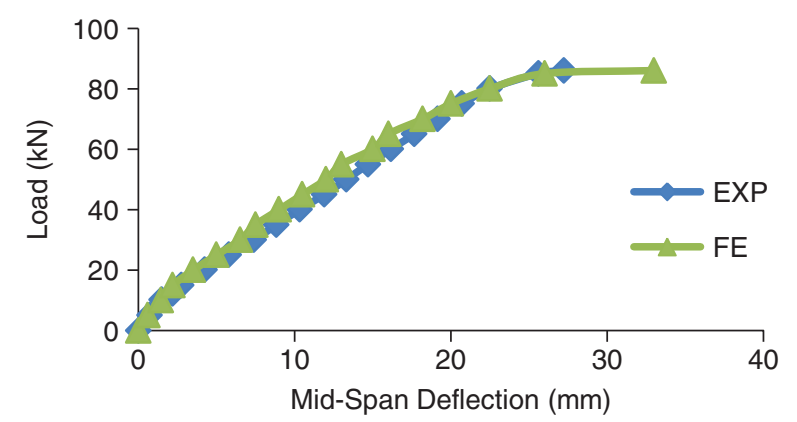

Fig. 21. Load against deflection curves for the pre-repair phase of the beam G4R3

The results show good agreement between analytical and experimental results, although analytical results show smaller deflection at loading range of $30 \mathrm{kN}$ until $70 \mathrm{kN}$. The analytical model results show that the beam fully failed at loading of $86 \mathrm{kN}$ with the steel reaching its rupture strain and the deflection being $33 \mathrm{~mm}$, while experiential results show that the beam failed, but did not collapse where the load against the defection curve started to become horizontal and the steel still did not reach the rupture strain. This is shown in Figure 22, which presents the load against steel strain curves.

The results show that the analytical results were compatible to the experimental results for the loading range less than $25 \mathrm{KN}$ and then started to have a smaller strain than the experimental results up to loading of $65 \mathrm{KN}$. When failure started to occur as indicated by the horizontal portion of the load against the defection curve, the load was released and the beam was repaired by fixing externally bonded CFRP sheets, after which the load was applied with cycles up to debonding of the CFRP sheets. The first cycle was up to the design load rate at $25 \mathrm{KN}$; the next cycle up to the steel yield load at $55 \mathrm{KN}$; then up to the failure load at $86 \mathrm{KN}$; then up to $115 \mathrm{KN}$ and $128 \mathrm{KN}$ when the intermediate crack induced debonding of the CFRP occurred. Figure 23 presents the load against cumulative deflection curves for the cycle loading.

The results show that analytical modelling has a higher deflection than the experimental approach. The intermediate crack induces debonding to occur at $128 \mathrm{kN}$ for both analytical and experiential results. At debonding, the analytical deflection was higher than the experimental

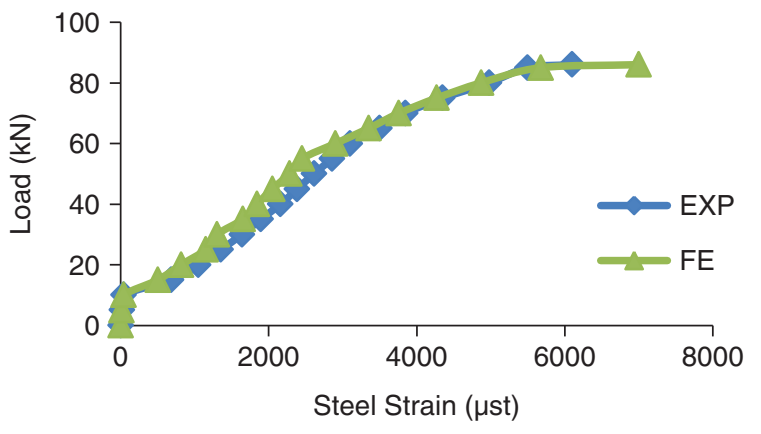

Fig. 22. Load against steel strain curves for the pre-repair phase of the beam G4R3

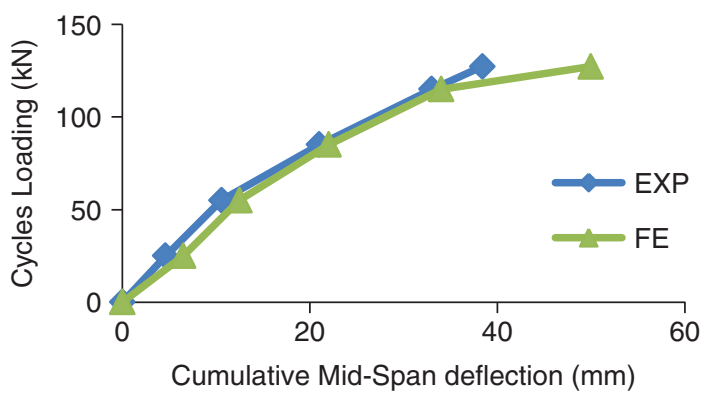

Fig. 23. Load against cumulative deflection curves for the repair cycle loading of the beam G4R3

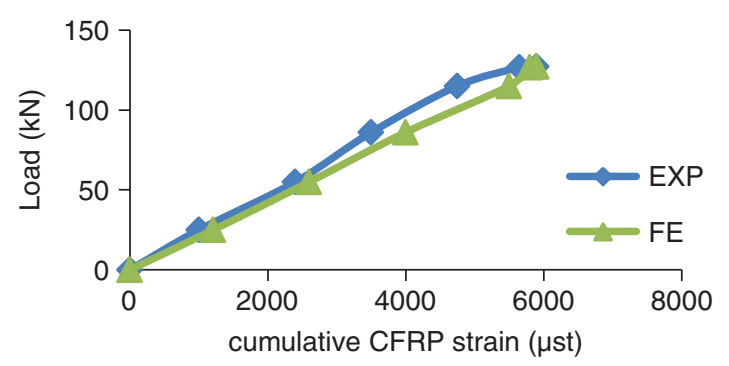

Fig. 24. Load against the cumulative CFRP strain for the postrepair phase of the beam G4R3

deflection, which is due to the steel strain status. Since the results show rupturing of the steel bar at the pre-repair phase of the beam, there was no record for the steel strain at the repairing phase. The CFRP strain was monitored and the load against the cumulative CFRP strain curves is shown in Figure 24.

The results show good agreement between analytical and experiential results, although analytical results show a higher strain, which is due to the pre-repair phase. At a prerepair phase, the analytical modelling considered rupturing of the steel bar, which influences the repairing phase by making the CFRP sheet take all the tension stresses on its own. The experiential results show that steel reinforcement did not reach the rupture strain when the failure started to occur, which influenced the repairing phase with the steel sharing some of the tension stresses with the CFRP sheets. Both results show that the CFRP debonding occurs at the loading rate of $128 \mathrm{kN}$ and the strain of $5900 \mu$ st. 


\section{Conclusions}

The present study aimed to investigate the effectiveness of repairing damaged $\mathrm{RC}$ beams with externally bonded CFRP sheets. The study was based on the comparison of the load against deflection, load against the steel strain and load against CFRP strain curves between unrepaired and repaired sections. The study also investigates the effect of the prerepair damage ratio on the repair effectiveness. Moreover, the present study compares the results carried out from the experimental approach with FE modelling and different design guidelines. Following are the main conclusions that can be drawn from on the results of the present study:

1) Repairing the beams with externally bonded CFRP sheets increases the carrying load and decreases the mid-span deflection and the steel strain.

2) A higher pre-repair damage level has a higher deflection and higher steel strain at the postrepair stages.

3) A higher pre-repair damage level has a higher CFRP strain for the loading cycles before CFRP debonding.

4) Repairing with externally bonded CFRP sheets will be effective and will increase the load capacity regardless of the pre-repair damage level.

5) There is smaller increase in load capacity for higher pre-repair damage level.

6) Smaller pre-repair damage level has higher CFRP debonding in order to achieve a higher increase in the load capacity.

7) Pre-repair cracks lead to intermediate crack induced failure modes for all the tested beams.

8) FE modelling is in good agreement with experimental approach results in terms of load against deflection, load against the steel strain, load against the CFRP strain, first crack load, steel yield load, failure load and failure modes. Although FE modelling shows that steel reaches its rupture strain when CFRP debonds, the experimental results show otherwise.

\section{Acknowledgements}

The authors would like to express their sincere thanks to University of Malaya (UM) and the Ministry of Higher Education (MOHE), Malaysia for the support given through research grant UM.C/625/1/HIR/MOHE/ENG/55. The authors would also like to thank all the people who have contributed either directly or indirectly, in making this research possible.

\section{References}

ACI 318. 2008. Building code requirements for structural concrete and commentary. Farmington Hills: American Concrete Institute.

ACI 440.2R. 2002. Guide for the design and construction of externally bonded FRP systems for strengthening concrete structures. Farmington Hills: American Concrete Institute.

Almakt, M. M.; Balasz, G. L.; Pilakoutas, K. 1998. Strengthening of RC elements by CFRP plate's local failure, in
Proceedings of the 2nd International Symposium in Civil Engineering, Budapest, Hungary. 8 p.

Arduini, M.; Nanni, A. 1997. Behavior of precracked RC beams strengthened with carbon FRP sheets, Journal of Composite for Construction ASCE 1(2): 63-70. http://dx.doi.org/10.1061/(ASCE)1090-0268(1997)1:2(63)

Benjeddou, O.; Ben Ouezdou, M.; Bedday, A. 2007. Damaged RC beams repaired by bonding of CFRP laminates, Construction and Building Materials 21(6): 1301-1310. http://dx.doi.org/10.1016/j.conbuildmat.2006.01.008

Bonacci, J. F.; Maalej, M. 2000. Externally bonded fiber reinforced polymer for rehabilitation of corrosion damaged concrete beams, ACI Structural Journal 97(5): 703-711.

Capozucca, R.; Cerri, M. N. 2002. Static and dynamic behaviour of RC beam model strengthened by CFRP-sheets, Construction and Building Materials 16(2): 91-99. http://dx.doi.org/10.1016/S0950-0618(01)00036-8

Ceroni, F. 2010. Experimental performances of RC beams strengthened with FRP materials, Construction and Building Materials 24(9): 1547-1559.

http://dx.doi.org/10.1016/j.conbuildmat.2010.03.008

Chajes, M. J.; Thomson, T. A.; Januszka, T. F.; Finch, W. W. 1994. Flexural strengthening of concrete beams using externally bonded composite materials, Construction and Building Materials 8(3): 191-201. http://dx.doi.org/10.1016/S0950-0618(09)90034-4

Choo, C. C.; Zhao, T.; Harik, I. 2007. Flexural retrofit of a bridge subjected to overweight trucks using CFRP laminates, Composites: Part B 38(5-6): 732-738. http://dx.doi.org/10.1016/j.compositesb.2006.06.020

Cromwell, J. R.; Harries, K. A.; Shahrooz, B. M. 2011. Environmental durability of externally bonded FRP materials intended for repair of concrete structures, Construction and Building Materials 25(5): 2528-2539. http://dx.doi.org/10.1016/j.conbuildmat.2010.11.096

Delpak, R. 2002. FRP strengthening of RC flexural members, ductility issues, A Presentation to ACIC 2002, 15 April 2002, Southampton.

El-Ghandour, A. A. 2011. Experimental and analytical investigation of CFRP flexural and shear strengthening efficiencies of RC beams, Construction and Building Materials 25(3): 1419-1429.

http://dx.doi.org/10.1016/j.conbuildmat.2010.09.001

Erki, M. A.; Meier, U. 1999. Impact loading of concrete beams externally strengthened with CFRP laminates, Journal of Composites for Construction ASCE 3(3): 117-124. http://dx.doi.org/10.1061/(ASCE)1090-0268(1999)3:3(117)

Fanning, P. J.; Kelly, O. 2001. Ultimate response of RC beams strengthened with CFRP plates, Journal of Composites for Construction ASCE 5(2): 122-127. http://dx.doi.org/10.1061/(ASCE)1090-0268(2001)5:2(122)

Heffernan, P. J.; Erki, M. A. 1996. Equivalents capacity and efficiency of reinforced concrete beams strengthened with carbon fibre reinforced plastic sheets, Canadian Journal of Civil Engineering 23(1): 21-29. http://dx.doi.org/10.1139/196-003

Kachlakev, D.; Miller, T.; Yim, S. 2001. Finite element modelling of reinforced concrete structures strengthened with FRP laminates. Final report SPR 316 for Oregon Department of Transportation and Federal Highway Administration, USA.

Kim, Y. J.; Brunell, G. 2011. Interaction between CFRPrepair and initial damage of wide-flange steel beams subjected to three-point bending, Composite Structures 93(8): 1986-1996. http://dx.doi.org/10.1016/j.compstruct.2011.02.024 
Klaiber, F. W.; Wipf, T. J.; Kempers, B. J. 2003. Repair of damaged prestressed concrete bridges using CFRP, in Proceedings of the Mid-Continent Transportation Research Symposium, August 2003, Ames, Iowa. 9 p.

Kutarba, M. P. 2004. Durability of carbon fiber reinforced polymer (CFRP) strengthening system used to repair corrosion damage in reinforced concrete: Master Theses in Engineering, University of Florida, USA.

Masoud, S.; Soudki, K.; Topper, T. 2001. CFRP-strengthened and corroded RC beams under monotonic and fatigue loads, Journal of Composites for Construction ASCE 5(4): 228-236. http://dx.doi.org/10.1061/(ASCE)1090-0268(2001)5:4(228)

Nguyen, D. M.; Chan, T. K.; Cheong, H. 2001. Brittle failure and bond development length of CFRP-concrete beams, Journal of Composites for Construction ASCE 5(1): 12-17. http://dx.doi.org/10.1061/(ASCE)1090-0268(2001)5:1(12)

Obaidat, Y. T.; Heyden, S.; Dahlblom, O. 2010. The effect of CFRP and CFRP/concrete interface models when modelling retrofitted RC beams with FEM, Composite Structures 92(6): 1391-1398. http://dx.doi.org/10.1016/j.compstruct.2009.11.008

Ombres, L. 2010. Prediction of intermediate crack debonding failure in FRP-strengthened reinforced concrete beams, Composite Structures 92(2): 322-329. http://dx.doi.org/10.1016/j.compstruct.2009.08.003

Rahimi, H.; Hutchinson, A. 2001. Concrete beams strengthened with externally bonded FRP plates, Journal of Composites for Construction ASCE 5(1): 44-56. http://dx.doi.org/10.1061/(ASCE)1090-0268(2001)5:1(44)
Ritchie, P. A.; Thomas, D. A.; Lu, L.-W.; Connely, G. M. 1991. External reinforcement of concrete beams using fiber reinforced plastics, ACI Structural Journal 88(4): 490-500.

Ross, C. A.; Jerome, D. M.; Tedesco, J. W.; Hughes, M. L. 1999. Strengthening of reinforced concrete beams with externally bonded composite laminates, ACI Structural Journal 96(2): 212-220.

Saadatmanesh, H.; Ehsani, M. R. 1991. RC beams strengthened with GFRP plates I: experimental study, Journal of Structural Engineering ASCE 117(11): 3417-3433. http://dx.doi.org/10.1061/(ASCE)0733-9445(1991)117:11 (3417)

Sharif, A.; Al-Sulaimani, G. J.; Basunbul, I. A.; Baluch, M. H.; Ghaleb, B. N. 1994. Strengthening of initially loaded reinforced concrete beams using FRP plates, ACI Structural Journal 91(2): 160-168.

Stallings, J. M.; Tedesco, J. W.; El-Mihilmy, M.; McCauley, M. 2000. Field performance of FRP bridge repairs, Journal of Bridge Engineering ASCE 5(2): 107-113. http://dx.doi.org/10.1061/(ASCE)1084-0702(2000)5:2(107)

Supaviriyakit, T.; Pornpongsaroj, P.; Pimanmas, A. 2004. Finite element analysis of FRP-strengthened RC beams, Songklanakarin Journal of Science and Technology 26(4): 497-507.

Triantafillou, T. C.; Plevris, N. 1992. Strengthening of RC beams with epoxy-bonded fiber-composite materials, Materials and Structures 25: 201-211. http://dx.doi.org/10.1007/BF02473064

Moatasem Mohammed FAYYADH. Post-Doctoral Research Fellow at the Department of Civil Engineering, the University of Malaya. He has been involved in several civil engineering projects as Project Engineer and Project Manager in Iraq, and as Structural Design Engineer in Malaysia. His research interests include structural damage identification using modal testing, CFRP repair assessment using both static load test and modal testing and finite element modelling of structural elements.

Hashim Abdul RAZAK. Professor of Structural Engineering at the Department of Civil Engineering, the University of Malaya. He has been involved in several major civil engineering projects as a consultant both locally and in the UK. His research interests include structural health monitoring, particularly with the application of modal analysis for damage identification in concrete structures. 